\title{
Nonglaucomatous optic neuropathies in Port Harcourt
}

This article was published in the following Dove Press journal:

Clinical Ophthalmology

6 October 201I

Number of times this article has been viewed

\section{Chinyere Nnenne \\ Pedro-Egbe' \\ SAH Cookey ${ }^{2}$ \\ Elizabeth A Awoyesuku \\ Nnenne $\mathrm{Ani}^{4}$ \\ 'Ophthalmology Unit, ${ }^{2}$ Department of Surgery, ${ }^{3}$ College of Health Sciences, University of Port Harcourt, ${ }^{4}$ Department of Ophthalmology, University of Port Harcourt Teaching Hospital, Port Harcourt, Nigeria}

Correspondence: Chinyere Nnenne Pedro-Egbe

Ophthalmology Unit, Department of Surgery, College of Health Sciences, University of Port Harcourt, Nigeria Tel +2348034070214

Fax +23484237904

Email cpegbe@weltekng.com
Aim: To review the types of nonglaucomatous optic neuropathies seen in Port Harcourt, Nigeria.

Materials and methods: Medical case records of all cases of nonglaucomatous optic neuropathy seen in the Eye Clinic of University of Port Harcourt Teaching Hospital, Port Harcourt, Nigeria over a 5-year period were reviewed. Relevant data including patient demography, presenting visual acuity and intraocular pressure, and fundus findings were extracted. Other details included central visual field analysis and color vision results. Cases of glaucomatous optic neuropathy were excluded.

Results: Ninety-nine cases of optic neuropathy were seen over this time period. There were 52 $(52.5 \%)$ males and 47 females. The mean age of those with optic neuropathy was $40 \pm 18.774$ years. Twenty-two patients $(22.2 \%)$ had bilateral involvement, while the rest were unilateral. About $40 \%$ of the patients with optic neuropathies had optic atrophy. Nutritional causes accounted for $31.3 \%$ and optic neuritis $27.3 \%$. Over $60 \%$ of the patients presented with visual acuities $\leq 6 / 60$. Most patients $(40 \%)$ had cecocentral scotoma.

Conclusion: Nonglaucomatous optic neuropathies resulting in optic atrophy is not uncommon in our environment and several factors may be implicated but the actual cause is difficult to determine because of late presentation of most patients.

Keywords: nonglaucomatous, optic neuropathies, Port Harcourt

\section{Introduction}

The diagnosis of optic neuropathy is usually made on clinical grounds and sometimes with the help of ancillary tests such as visual field analysis and optical coherence tomography. Rarely can the etiology of optic neuropathy be made on the basis of a single clinical finding because there is considerable overlap of clinical features between even the relatively common optic neuropathies. ${ }^{1,2}$ It is said that in experienced hands, clinical diagnosis is reliable and sufficient, and further investigation is not required. ${ }^{3}$ The clinical diagnosis of optic neuropathies is based on the association of visual loss, altered color vision, visual field defect, and relative afferent papillary defect (if the optic neuropathy is unilateral). ${ }^{4}$ Pathologic cupping of the optic nerve is most commonly associated with glaucomatous optic neuropathy but other types of optic neuropathies have also been reported to cause cupping of the optic disk; conditions such as ischemic optic neuropathy, ${ }^{5}$ intracranial tumors ${ }^{6}$ and optic neuritis. ${ }^{7}$ Clinically, clues such as optic nerve head pallor can be useful in distinguishing glaucomatous from nonglaucomatous optic nerve head cupping. ${ }^{8}$

The onset of optic neuropathy is not always clear. Inflammatory optic neuropathy tends to have a subacute onset over a number of days, frequently accompanied by 
periocular pain exacerbated by eye movements. ${ }^{9}$ The almost complete recovery of vision over the next few weeks is sufficiently characteristic of the vast majority of cases of demyelinating optic neuropathy to allow a clinical diagnosis, without the need for confirmatory investigation as long as there are no atypical features. ${ }^{10,11}$ Compressive optic neuropathy usually causes gradually progressive visual loss, although vascular lesions may cause abrupt visual decline occasionally, followed by some recovery. Nutritional or toxic optic neuropathy results in subacute or chronic symmetrical bilateral visual loss. Visual loss due to congenital anomalies rarely changes over time.

The ability to differentiate glaucomatous from nonglaucomatous cupping is usually difficult even with experience, however, evaluation of parapapillary chorioretinal atrophy has been found to be useful in differentiating both types of optic neuropathy. ${ }^{12}$ Some researchers in the US ${ }^{13}$ analyzed four optic disk features in order to distinguish nonglaucomatous from glaucomatous optic neuropathy and found neuroretinal rim pallor to be $94 \%$ specific for nonglaucomatous atrophy, while focal or diffuse obliteration of the neuroretinal rim was $87 \%$ specific for glaucoma. These two signs were said to be the most useful in making the distinction between glaucomatous and nonglaucomatous atrophy. Thinning of the rim was, however, more common in glaucomatous atrophy and laminar dots were said to be present in both types of excavation. ${ }^{13}$ Also, glaucomatous optic neuropathy is not symptomatic until late in the disease course such that it is usually identified incidentally or by screening. ${ }^{14}$

The anterior visual pathway is susceptible to damage from toxins or nutritional deficiencies. This causes a type of optic neuropathy referred to as tobacco-alcohol amblyopia which is characterized by central or cecocentral scotoma. ${ }^{15}$ Toxic/nutritional optic neuropathy is quite common in

Table I Age and gender distribution of patients with optic neuropathy

\begin{tabular}{llll}
\hline $\begin{array}{l}\text { Age group } \\
\text { (years) }\end{array}$ & Sex & & \\
\cline { 2 - 4 } & Male (\%) & Female (\%) & Total (\%) \\
\hline$<10$ & $9(9.1 \%)$ & $3(3.0 \%)$ & $3(3.0 \%)$ \\
$10-19$ & $18(18.2 \%)$ & $10(10.1 \%)$ & $15(15.2 \%)$ \\
$20-29$ & $6(6.1 \%)$ & $6(6.1 \%)$ & $28(28.3 \%)$ \\
$30-39$ & $4(4.0 \%)$ & $4(4.0 \%)$ & $12(12.1 \%)$ \\
$40-49$ & $5(5.0 \%)$ & $10(10.1 \%)$ & $15(15.2 \%)$ \\
$50-59$ & $7(7.1 \%)$ & $5(5.1 \%)$ & $12(12.1 \%)$ \\
$60-69$ & $3(3.0 \%)$ & $2(2.0 \%)$ & $5(5.0 \%)$ \\
$70-79$ & & $1(1.0 \%)$ & $1(1.0 \%)$ \\
$80-89$ & $52(52.5 \%)$ & $47(47.5 \%)$ & $99(100 \%)$ \\
Total & & &
\end{tabular}

Table 2 Corrected visual acuity of affected eyes

\begin{tabular}{llll}
\hline Visual acuity & Right eye (\%) & Left eye (\%) & Total (\%) \\
\hline $6 / 12$ & $6(3.9 \%)$ & $8(5.2 \%)$ & $14(9.0 \%)$ \\
$6 / 18$ & $9(5.8 \%)$ & $5(3.2 \%)$ & $14(9.0 \%)$ \\
$6 / 24$ & $7(4.5 \%)$ & $7(4.5 \%)$ & $14(9.0 \%)$ \\
$6 / 36$ & $9(5.8 \%)$ & $8(5.2 \%)$ & $17(11.0 \%)$ \\
$6 / 60$ & $12(7.7 \%)$ & $16(10.3 \%)$ & $28(18.0 \%)$ \\
CF & $10(6.5 \%)$ & $12(7.7 \%)$ & $22(14.2 \%)$ \\
HM & $15(9.7 \%)$ & $6(3.9 \%)$ & $21(13.6 \%)$ \\
LP & $1(0.6 \%)$ & $3(1.9 \%)$ & $4(2.6 \%)$ \\
NPL & $13(8.4 \%)$ & $8(5.2 \%)$ & $21(13.6 \%)$ \\
Total & $82(52.9 \%)$ & $73(47.1 \%)$ & $155(100 \%)$ \\
\hline Ab &
\end{tabular}

Abbreviations: CF, counting fingers; HM, hand movement; LP, light perception; NPL, no perception of light.

conditions of chronic alcohol abuse and malnutrition especially during times of war or famine as was the case in Cuba in the early 1990s. ${ }^{16}$

\section{Materials and methods}

Medical case records of all cases of nonglaucomatous optic neuropathy seen in the Eye Clinic of University of Port Harcourt Teaching Hospital (UPTH) over a 5-year period (January 2006-December 2010) were reviewed. Relevant data including age, sex, corrected visual acuity (Snellen chart), and intraocular pressure (Perkins MK 2 Hand held applanation tonometer; HS Clemens Clarke International, Essex, UK), and fundus findings (slit-lamp biomicroscopy with $+78 \mathrm{D}$ ) were extracted from the records. Other details were their central visual field analysis (Humphrey visual field analyzer, Model 740; Carl Zeiss Ophthalmic Systems Inc, Dublin, CA) and color vision results (Ishihara pseudoisochromatic color plates). Exclusion criteria included all cases of glaucomatous optic neuropathy (based on abnormal central visual field results [Humphrey perimetry], vertical cup/disk ratio $>0.5$, with or without elevated intra-ocular pressure). Data was analyzed using Epi Info (v 6.02; Centers for Disease Control and Prevention, Atlanta, GA) and $P$ values $<0.05$ were considered significant.

\section{Results}

Table 1 shows the age and gender distribution of patients who were diagnosed with optic neuropathy during the period under review. A total of 99 cases of optic neuropathy

Table 3 Types of optic neuropathy

\begin{tabular}{ll}
\hline Types of optic neuropathy & Number (\%) \\
\hline Optic atrophy (most causes unknown) & $41(41.4 \%)$ \\
Optic neuritis & $27(27.3 \%)$ \\
Nutritional optic neuropathy/unknown & $31(31.3 \%)$ \\
Total & $99(100)$ \\
\hline
\end{tabular}


Table 4 Fundus findings

\begin{tabular}{ll}
\hline Fundus picture & Number (\%) \\
\hline Pink/hyperemic disk & $20(20.2 \%)$ \\
Temporal disk pallor & $31(31.3 \%)$ \\
Pale neuroretinal rim & $41(41.4 \%)$ \\
Blurred disk margins & $7(7.1 \%)$ \\
Total & $99(100 \%)$ \\
\hline
\end{tabular}

were seen over a 5 -year period. There were $52(52.5 \%)$ males and $47(47.5 \%)$ females giving a male:female ratio of 1.1:1. The mean age of those with optic neuropathy was $40 \pm 18.77$ years. Over $55 \%$ of those with optic neuropathy were aged between 10 and 39 years old. Those in the age group 20-29 years were the most affected (28.3\%) and in this particular group, males were about twice as affected as females (male:female $=1.8: 1$ ). The least affected were those in both extremes of ages $(<10$ years old: $3 \%$; 80-89 year olds: $1 \%)$.

Table 2 shows the corrected visual acuity of the study subjects. The right eye was involved in 82 cases $(52.9 \%)$ and the left eye in 73 cases (47.1\%). Twenty-two patients (22.2\%) had bilateral involvement while $77.8 \%(\mathrm{~N}=77)$ had unilateral involvement. Altogether, 155 eyes of 99 patients were involved. Over $60 \%$ of the patients presented with visual acuities $\leq 6 / 60$, only 14 patients had $\mathrm{VA} \geq 6 / 18$.

Table 3 shows the types of optic neuropathy in this study. About $40 \%$ of the patients had optic atrophy at presentation. Optic neuritis (retrobulbar neuritis and papillitis) accounted for $27.3 \%$ of cases, while the rest $(31.3 \%)$ were due mainly to nutritional causes (on account of temporal disk pallor) and some unknown causes. The mean age of those with optic atrophy was $41.35 \pm 18.28$ years and for those with optic neuritis $26.67 \pm 12.10$ years.

Only 65 patients had perimetry. The remaining 34 did not because of severe optic atrophy. Table 5 shows that most patients $(40 \%)$ had cecocentral scotoma followed by generalized depression of sensitivity (15.3\%). Enlargement of the blindspot and central scotoma were noted in five cases each. Of the 20 patients who had pink/ hyperemic disks, fifteen (25.9\%) had normal central visual field (CVF) results.

\section{Discussion}

Optic atrophy was the most common type of nonglaucomatous optic neuropathy reported in this study. This is much higher than the study by Gupta et al, ${ }^{8}$ however, a similarity between this study and that by Gupta et al was that most of our patients were also in their early forties. In their study, only twelve patients were studied and this could account for the small number of patients with optic atrophy. In addition, patients in our setting tended to report late for treatment and this may account for the large number of cases of optic atrophy as these patients may be seen at the terminal end of the disease process.

Cassava and cassava products are staple foods in southern Nigeria and there is good evidence that it causes optic neuropathy because of its high cyanide content. ${ }^{17,18}$ Could this be the case with some of our patients? This could also explain the large number of cases of nutritional optic neuropathy seen in this study. A characteristic of patients in our environment is the tendency to withhold important information about their health especially if they think it may be blamed for their illness. Despite this, there is the likelihood that chronic alcohol consumption and nutritional deficiency may play important roles in some of the cases of optic neuropathy seen because illicit gin is brewed and consumed in large quantities in this environment. Even though many cases of optic atrophy were seen, it was difficult to say for certain what the exact causes were but they were certainly not glaucomatous based on the exclusion criteria; most looked to be due to secondary causes such as resolved disk edema. All cases of optic neuropathy occurred in isolation. We did not record any cases of hereditary optic neuropathy and there was also no evidence of a compressive lesion in any of our cases. It is not entirely certain if some of the neuropathies could have been due to ischemic optic neuropathy as a few of the fundus pictures revealed slightly hyperemic disks.

Table 5 Central visual field analysis (Humphrey)

\begin{tabular}{llllllll}
\hline Fundus picture & Number & $\begin{array}{l}\text { Normal } \\
\text { CVF }\end{array}$ & $\begin{array}{l}\text { Central } \\
\text { scotoma }\end{array}$ & $\begin{array}{l}\text { Cecocentral } \\
\text { scotoma }\end{array}$ & $\begin{array}{l}\text { Altitudinal } \\
\text { defect }\end{array}$ & $\begin{array}{l}\text { Generalized depression } \\
\text { of sensitivity }\end{array}$ & $\begin{array}{l}\text { Enlargement } \\
\text { of blind spot }\end{array}$ \\
\hline Temporal disk pallor & $3 \mathrm{I}$ & - & $5(7.7 \%)$ & $26(40 \%)$ & - & - & - \\
Blurred disk margins & 7 & - & - & - & - & $2(3.0 \%)$ & $5(7.7 \%)$ \\
Pink/hyperemic disk & 20 & $15(23.1 \%)$ & - & - & $4(6.2 \%)$ & $1(1.5 \%)$ & - \\
Optic atrophy & 7 & - & - & - & - & $7(10.8 \%)$ & - \\
Total & $65(100 \%)$ & I5 (23.1\%) & $5(7.7 \%)$ & $26(40 \%)$ & $4(6.2 \%)$ & $3(15.3 \%)$ & $5(7.7 \%)$ \\
\hline
\end{tabular}

Abbreviation: CVR, control visual field. 
One of the major limitations of this study is the fact that none of our patients had an Optical Coherence Tomography (OCT) to properly assess the retinal nerve fiber layer which would have helped in characterizing the different types of optic neuropathies. OCT would also have assisted in categorically differentiating glaucomatous from nonglaucomatous optic neuropathy.

\section{Conclusion}

Nonglaucomatous optic neuropathies resulting in optic atrophy are not uncommon in our environment and several factors may be implicated but this is difficult to know because of the late presentation of most patients. A prospective study is proposed in future and should be able to address this issue as this may be part of the exclusion criteria.

\section{Disclosure}

The authors report no conflicts of interest in this work.

\section{References}

1. Rizzo JF 3rd, Lessell S. Optic neuritis and ischemic optic neuropathy. Overlapping clinical profiles. Arch Ophthalmol. 1991;109:1668-1672.

2. Levin LA, Rizzo JF 3rd, Lessell S. Neural network differentiation of optic neuritis and anterior ischaemic optic neuropathy. Br J Ophthalmol. 1996;80:835-839.

3. Van Stavern GP, Newman NJ. Optic neuropathies. An overview. Ophthalmol Clin North Am. 2001;14:61-71, viii.

4. Behbehani R. Clinical approach to optic neuropathies. Clin Ophthalmol. 2007;1:233-246.
5. Danesh-Meyer HV, Savino PJ, Sergott RC. The prevalence of cupping in end-stage arteritic and nonarteritic anterior ischemic optic neuropathy. Ophthalmology. 2001;108:593-598.

6. Blumenthal EZ, Girkin CA, Dotan S. Glaucomatous-like cupping associated with slow-growing supra-sellar intracranial lesions. Neuro-Ophthalmology. 2006;30:111-115.

7. Piette SD, Sergott RC. Pathological optic-disc cupping. Curr Opin Ophthalmol. 2006;17:1-6.

8. Gupta PK, Asrani S, Freedman SF, El-Dairi M, Bhatti MT. Differentiating glaucomatous from non-glaucomatous optic nerve cupping by optical coherence tomography. Open Neurol J. 2011;5:1-7.

9. Swartz NG, Beck RW, Savino PJ, et al. Pain in anterior ischemic optic neuropathy. J Neuroophthalmol. 1995;15:9-10.

10. Optic Neuritis Study Group. The clinical profile of optic neuritis. Experience of the Optic Neuritis Treatment Trial. Arch Ophthalmol. 1991;109:1673-1678.

11. Lee AG, Lin DJ, Kaufman M, Golnik KC, Vaphiades MS, Eggenberger E. Atypical features prompting neuroimaging in acute optic neuropathy in adults. Can J Ophthalmol. 2000;35:325-330.

12. Jonas JD, Fernandez MC, Naumann GOH. Parapapillary atrophy and retinal vessel diameter in non-glaucomatous optic nerve damage. Invest Ophthalmol Vis Sci. 1991;32:2942-2947.

13. Trobe JD, Glaser JS, Cassady J, Herschler J, Anderson DR. Nonglaucomatous excavation of the optic disc. Arch Ophthalmol. 1980; 98:1046-1050.

14. Riordan-Eva P. Clinical assessment of optic nerve disorders. Eye (Lond). 2004;18:1161-1168.

15. Zafar A, Roy H Sr. Toxic/nutritional optic neuropathy. Medscape. Updated August 27, 2008. Available at: http://emedicine.medscape. com/article/1217661-overview. Accessed on September 20, 2011.

16. Sadun AA, Martone JF, Muci-Mendoza R, et al. Epidemic optic neuropathy in Cuba: eye findings. Arch Ophthalmol. 1994;112: 691-699.

17. Osuntokun BO, Osuntokun O. Tropical amblyopia in Nigerians. Am J Ophthalmol. 1971;72:708-716.

18. Wilson J, Linnell JC, Matthews DM. Plasma-cobalamins in neuro-ophthalmological diseases. Lancet. 1971;1:777-778.
Clinical Ophthalmology

\section{Publish your work in this journal}

Clinical Ophthalmology is an international, peer-reviewed journal covering all subspecialties within ophthalmology. Key topics include: Optometry; Visual science; Pharmacology and drug therapy in eye diseases; Basic Sciences; Primary and Secondary eye care; Patient Safety and Quality of Care Improvements. This journal is indexed on

\section{Dovepress}

PubMed Central and CAS, and is the official journal of The Society of Clinical Ophthalmology (SCO). The manuscript management system is completely online and includes a very quick and fair peer-review system, which is all easy to use. Visit http://www.dovepress.com/ testimonials.php to read real quotes from published authors. 